\title{
Power Loss Minimization for Distribution Networks with Load Tap Changing Using Genetic Algorithm and Environmental Impact Analysis
}

\author{
Talha Enes GÜMÜŞ*, Ceyda AKSOY TIRMIKÇI, Cenk YAVUZ, Mehmet Ali YALÇIN, Mustafa TURAN
}

\begin{abstract}
This paper presents an investigation of the IEEE 34 bus test system benefits with deployment of distribution static compensator (DSTATCOM) and distributed generation (DG) in the aspect of power loss minimization, bus voltage stability and greenhouse gas emission mitigation. Power loss minimization is carried out by adjusting tap changer positions of the load tap changing transformer with one of the well-known metaheuristic algorithms, Genetic Algorithm (GA). To check the voltage stability of the system after minimization, bus voltage profile index is developed. Similarly, environmental profile is evaluated by three different indices. The behaviour of the system is analysed for four different cases as follows. In Case 1, voltage and reactive power control is provided by capacitor banks. In Case 2, capacitor banks are replaced with DSTATCOM. In Case 3 and Case 4, Case 1 and Case 2 are reinvestigated in the presence of additional DG. All cases are evaluated with both traditional Newton- Raphson optimization algorithm and evolutionary-based GA optimization algorithm. The results indicate that GA optimization provides more energy savings than traditional optimization in all cases with bus voltage index within the allowed range. Besides voltage profile of the system in all cases with two algorithms supports the fact that evolutionary-based metaheuristics offer the best choices for a non-linear optimization problem in comparison with the traditional optimization methods. The overall results reveal that Case 4 , test system with DSTATCOM and DG, is the best case which provides minimum power losses and a significant amount of emission savings with greenhouse payback time (GPBT) of 0.458 years.
\end{abstract}

Keywords: bus voltage stability; distributed generation; distribution static compensator; emission mitigation; Genetic Algorithm; Load tap changing; power loss minimization

\section{INTRODUCTION}

Access to energy is vital for every community on account of developing technology and increasing population. Thus, priority of distribution companies is to provide secure and uninterrupted energy to consumers. However, the behaviour of distribution networks is becoming more instantaneous everyday by the integration of distributed generation with increasing penetration levels due to climate change concerns. As networks are diversified with new technologies, more advanced techniques are required for voltage and reactive power control.

In distribution networks, tap changers, voltage regulators and adjustable capacitor banks are presented as the conventional controllers which are used to improve the energy efficiency by node voltages at acceptable range for many years. Thus, power loss optimization becomes a nonlinear, complicated integer programming problem accompanied with nonlinear power flow equations, limited variables and other limitations [1-3]. Leisse et al. [4] propose that the use of on-load tap changers at the consumption point is advantageous for voltage stability, especially in the presence of distribution generation units. Simulation results prove that the control method allows to benefit from distribution generation at maximum capacity with acceptable network losses. Szuvovivski et al. [5] present an optimal power flow algorithm which allocates capacitor banks and voltage regulators at the same time to improve the voltage profile and power factor of the network. The results indicate that allocation of voltage regulators and capacitor banks offers a good solution of power losses and voltage profile. Bravo et al. [6] emphasise that networks need shunt capacitor support for voltage and reactive power control in the customer side, unless the Volt/Var features of inverters are improved.

In recent years an alternative device necessity raised, since the responses of conventional power conditioning devices are not fast enough to meet support to the network with high distributed generation penetration levels. Jie et al. [7] propose a new method to provide the coordination between inverters and flexible AC transmission system devices (FACTS). The priority in the method is to control voltage fluctuations immediately with a stable control behaviour. Yu et al. [8] establish a sliding mode control strategy to control load frequency and voltage with a commonly used FACTS device, Static Var Controller. The results show that the proposed method provides the stability in selected parameters more effectively in comparison with conventional strategies. Shaik et al. [9], develop a systematic method to place FACTS devices optimally to minimize the cost. The simulation results indicate that the system with optimally placed controllers still operates at acceptable voltage range with minimum power losses.

As the studies above prove clearly, power loss minimization is a non-linear optimization problem with precise voltage constraints. Evolutionary-based metaheuristics and swarm intelligence algorithms become prominent as the best choices to solve power system objective functions, since traditional algorithms fit linear objective functions more properly. The purpose of this study is to investigate real power losses of IEEE 34 bus test system for four different cases by adjusting tap changer positions of the load tap changing transformer by using one of the well-known metaheuristic algorithms, Genetic Algorithm (GA). For this purpose, tap value formulation is established to minimize power losses by keeping bus voltages within allowed limits. The new formulation is applied to IEEE 34 bus test system for four different cases with traditional optimization and GA optimization. The results of the cases for both optimization methods are compared in terms of power loss minimization, voltage profile and environmental profile. In conclusion, it is observed that Case 4 test system with DSTATCOM and DG, with GA optimization provides maximum power savings together with acceptable bus voltage profile and environmental profile. 
The organization of the paper is as follows. Section II introduces the system description and test cases. Section III explains the tap value formulation of load tap changing transformer with minimum power loss objective function and voltage constraints. Section IV presents a discussion regarding application of nature-inspired metaheuristic optimization techniques and an explanation for GA algorithm is implemented in this paper. Section V introduces fitness functions developed to evaluate the voltage and environmental profiles of the system in all test cases. Section VI gives the results for all cases with both traditional optimization algorithm and evolutionary-based optimization algorithm, GA. Section VII presents the conclusions.

\section{SYSTEM DESCRIPTION}

For the present work, the simulation study is carried out on IEEE 34 bus test system. The main reason to select IEEE 34 bus test system is to evaluate the proposed algorithm with a system with two different tap load changing transformers. However, the proposed algorithm can be used for all test systems and real systems with tap load changers. The one-line diagram of IEEE 34 bus test system is illustrated in Fig. 1. The test system has one $69 / 24.9 \mathrm{kV}$ transformer, two 24/4.16 kV voltage regulators, one $100 \mathrm{kVar}$ capacitor bank at bus 844 and one $150 \mathrm{kVar}$ capacitor bank at bus 848. In the given test system, voltage regulators are allowed to set the voltage between 0.9 - 1.1 pu with 32 different voltage levels. Each level change makes a $0.625 \%$ pu change in the voltage.

In this work real power losses of the test system are determined by adjusting 24 - hour tap values of tap changer for the following cases:

- Case 1: Test system with capacitor banks,

- Case 2: Test system with DSTATCOM,

- Case 3: Test system with distributed generation and capacitor banks,

- Case 4: Test system with distributed generation and DSTATCOM.

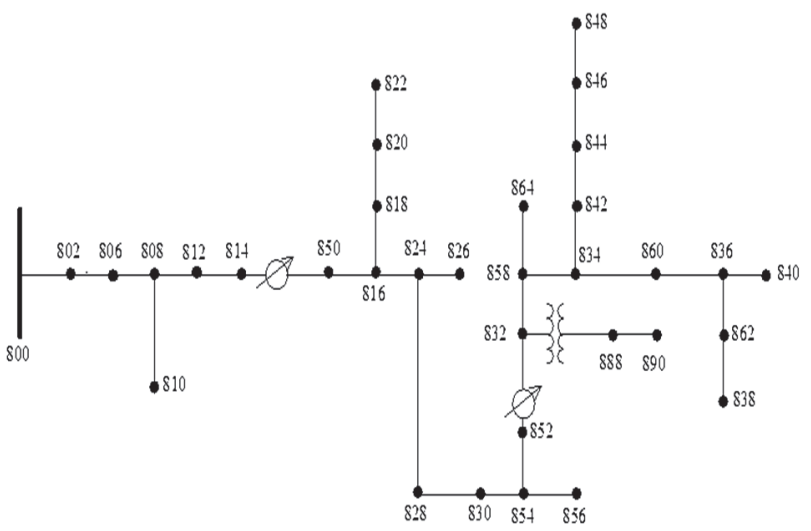

Figure 1 The one-line diagram of the IEEE 34 bus test system [13]

In recent years reactive power compensation and voltage control have become vital since the unsteady power generation is observed with increasing distributed generation [11]. Therefore, FACTS devices, which can generate the reactive power when required, independently from the present voltage value, have come into prominence instead of traditional compensation methods [12]. As capacitor banks of the test system, $100 \mathrm{kVar}$ and $150 \mathrm{kVar}$ banks are located on buses 844 and 848 respectively. DSTATCOM is selected to have the same power value with the capacitor banks available in the system. Fig. 2 illustrates the circuit scheme of DSTATCOM, a coupling transformer, a voltage source inverter and a DC power storage device.

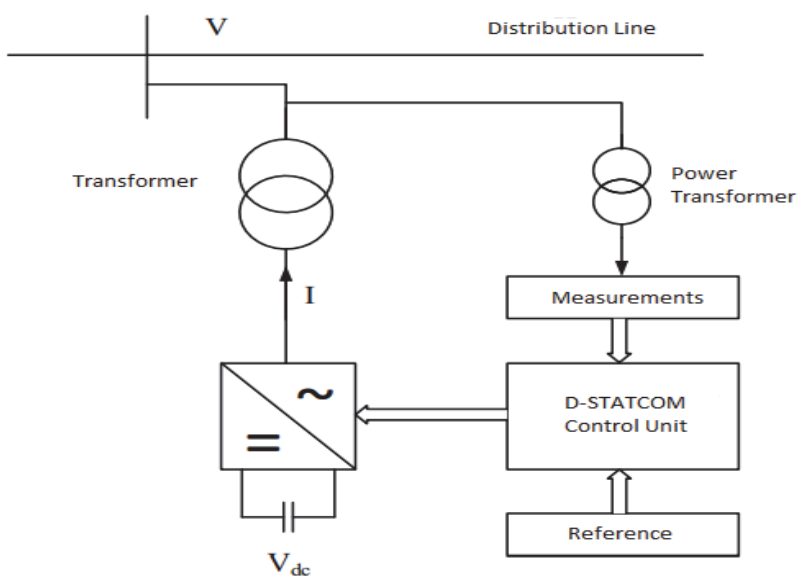

Figure 2 Basic structure of DSTATCOM

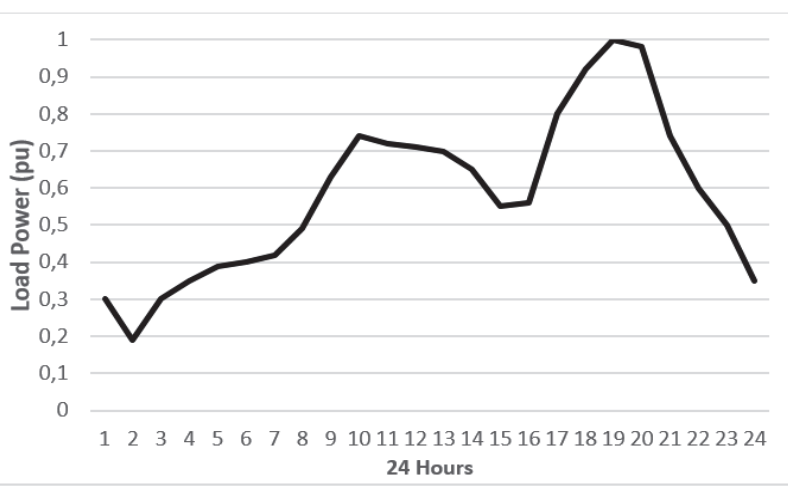

Figure 324 - hour load power demand curve [12]

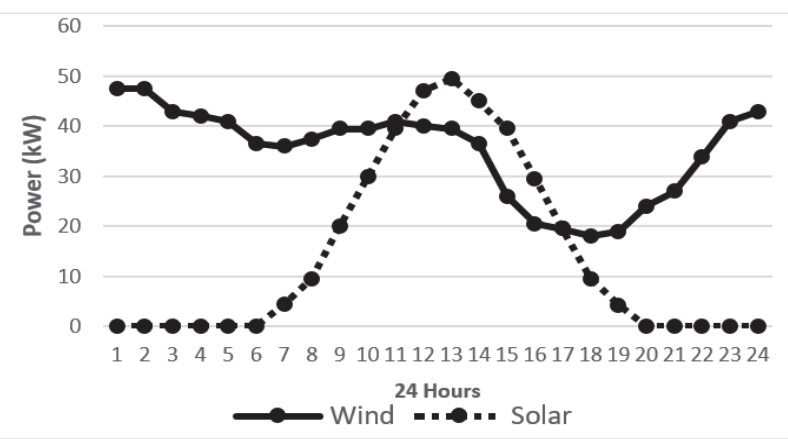

Figure 424 - Hour power curve of distributed generation [14]

As distributed generation, the present wind and solar energy systems of the test system, one $50 \mathrm{~kW}$ wind turbine on bus 814 and one $50 \mathrm{~kW}$ solar panel on bus 828 , are used.

Fig. 3 and Fig. 4 illustrate 24 - hour time load power demand curve and power generation curve of related distributed generation respectively.

\section{TAP VALUE FORMULATION}

Real power losses in distribution networks are equal to the difference between the generated active power and the consumed real power. Therefore, (1) is selected as the 
objective function of the present real power optimization problem in this work [15-17]:

$$
\begin{aligned}
& P_{\text {loss }}=\sum_{i=1}^{n b} P_{G i}-\sum_{i=1}^{n_{b}} P_{L i}= \\
& =\sum_{i=1}^{n b} \sum_{i=1}^{n_{b}} V_{i} V_{j} Y_{i j} \cos \left(\theta_{i j}+\delta_{i j}\right)
\end{aligned}
$$

In this equation $P_{G i}$ and $P_{L i}$ are the generated active power and consumed active power, $Y_{i j}$ and $\theta_{i j}$ are the magnitude and angle of the admittance between $i$-th and $j$ th buses, $V_{i}$ and $V_{j}$ are the magnitude of $i$-th and $j$-th bus voltage, $\delta_{i i}$ is the phase angle.

In IEEE 34 bus test system, tap changer positions of the two-load tap changing transformers and the on/off conditions of the capacitor banks or FACTs devices are discrete variables which are utilized as power conditioning units for voltage and reactive power. Thus, it is proposed that a non-linear problem approach is more accurate to minimize power losses of the present test system with stable bus voltages [14].

In real power loss minimization optimization problems, power flow equations are assumed as equality constraints. $g(x, u)$ presents power flow equations in all cases:

$g(x, u)=0$

$\Delta P_{i}=P_{g i}-P_{l i}-P_{i}=0$

$\Delta Q_{i}=Q_{g i}-Q_{l i}-Q_{i}=0$

Active power, $P_{i}$ and reactive power, $Q_{i}$, are defined as follows:

$$
\begin{aligned}
& P_{i}=V_{i} \sum_{j=0}^{n b} V_{j}\left(\cos \theta_{i j} G_{i j}+\sin \theta_{i j} B_{i j}\right) \\
& Q_{i}=V_{i} \sum_{j=0}^{n b} V_{j}\left(\cos \theta_{i j} G_{i j}-\cos \theta_{i j} B_{i j}\right)
\end{aligned}
$$

where $G_{i j}$ and $B_{i j}$ are the real and imaginary parts of admittance matrix respectively.

In distribution networks, admittance matrix is calculated as in Eq. (7) by using pi equivalent circuit given in Fig. 5, when a load tap changing transformer is present.

$$
\begin{aligned}
& y_{i j}=a y_{i j}, y_{i i}=a^{2} y_{i j}, y_{j j}=y_{i j} \\
& y_{i j}=y_{j i}=G_{i j}+j B_{i j} v e Y_{i i}=G_{i i}+j B_{i i}
\end{aligned}
$$

where a is tap ratio and defined as in Eq. (8) in terms of tap position of the transformer, tap.

$$
a=V_{0}+\operatorname{tap} \Delta_{\text {tap }}, \Delta_{\text {tap }}=1+\operatorname{tap} 0.00625
$$

Tap ratio explains the relationship between the input voltage and output voltage of a load tap changing transformer. Each transformer present in this work is capable of changing the voltage level $\pm 10 \%$ with 16 tap positions. Therefore, the voltage level can be changed $\pm 20 \%$ with 32 tap positions by two tap changers. Power

flow equations of the bus where load tap changing transformer is present, are defined as follows:

$$
\begin{aligned}
& P_{i j}=a^{2} V_{i}^{2} G_{i i}+a V_{i} V_{j}\left(\cos \theta_{i j} G_{i j}+\sin \theta_{i j} B_{i j}\right) \\
& Q_{i j}=-a^{2} V_{i}^{2} B_{i i}+a V_{i} V_{j}\left(\sin \theta_{i j} G_{i j}-\cos \theta_{i j} B_{i j}\right) \\
& P_{i j}=V_{i}^{2} G_{i i}+V_{i} V_{j} a\left(\cos \theta_{i j} G_{i j}+\sin \theta_{i j} B_{i j}\right) \\
& Q_{i j}=V_{i}^{2} B_{i i}+V_{i} V_{j} a\left(\sin \theta_{i j} G_{i j}-\cos \theta_{i j} B_{i j}\right)
\end{aligned}
$$

Figure 5 Tap changer transformer pi equivalent circuit

In this work capacitor banks of the test system are added as inequality constraint, $Q_{g i}$, to the optimization problem in Case 1 and Case 3:

$Q_{g i}=c_{i} Q_{i}^{c a p}$

where $Q_{i}^{c a p}$ defines the capacitor power and $c_{i}$ defines the number of on/off levels of capacitor banks.

In Case 2 and Case 4, reactive power limitations of DSTATCOM are added to the optimization problem as inequality constraint instead of capacitor banks in Eq. (13):

$\left[Q_{\min }\right] \leq\left[Q_{\text {DSTATCOM }}\right] \leq\left[Q_{\max }\right]$

In a power flow problem which is optimized by Eq. (17), state variable and control variable are defined as: $x=\left[\begin{array}{l}Q \\ V\end{array}\right]$ and $u=\left[\begin{array}{c}\text { tap } \\ \text { cap }\end{array}\right]=\left[\begin{array}{c}\text { tap } \\ c\end{array}\right]$ respectively.

Control variable, $u$, checks if capacitor bank is on or off and determines the level of tap changer. Lower and upper limits of $u$ are as follows:

$\left[u_{\min }\right] \leq[u] \leq\left[u_{\max }\right]$

Lower and upper limits of the tap position are as follows:

$\left[\operatorname{tap}_{\min }\right] \leq[$ tap $] \leq\left[\operatorname{tap}_{\max }\right]$

$[-16] \leq[$ tap $] \leq[$ tap $]$

Lower and upper limits of the number of on/off levels of capacitor banks are as follows:

$[0] \leq\left[c_{i}\right] \leq\left[N_{c a p}\right]$ 
The on/off condition for a capacitor is defined as follows:

$$
[0] \leq\left[c_{i}\right] \leq[1]
$$

Finally, bus voltages are added to the problem as inequality constraint $[19,20]$ :

$$
\left[\left|V_{\min }\right|\right] \leq[|V|] \leq\left[\left|V_{\max }\right|\right]
$$

In this paper, the main purpose is to minimize real power losses by optimizing tap values of load tap changing transformers while all bus voltages are within the allowed limits and the consumed power by each load bus is constant in the non-linear power flow equations given above.

\section{GENETIC ALGORITHM OPTIMIZATION}

Lately, nature-inspired metaheuristic optimization techniques are widely used for solving complex real-life optimization problems in varying applications of different areas [21-29]. There are many applications of the evolutionary-based metaheuristics and swarm intelligence algorithms in the electric power industry for significant problems. Renewable energy sources are expected to grow in near future, due to the rapid increase in energy demand and depletion of fossil fuels. Therefore, an incorporation of renewable energy systems to the network comes to the front as emerging trend for sustainability. However, uncertainty of the outputs by both solar and wind energy systems creates various practical concerns in terms of reliability, economic, technical, environmental and social measures. Wang et al. [30] use a mixed-integer multiobjective particle swarm optimization technique to design an optimum hybrid generating system with minimum cost and maximum reliability. Zang et al. [31] propose an advanced particle swarm optimization algorithm to improve the power output by tracking the wind velocity and solar radiation of a wind/photovoltaic hybrid power system. Abdelkader et al. [32] develop a multi-objective based Genetic Algorithm to size a hybrid power system with a hybrid energy storage system in terms of economic profitability and power quality.

The power factor is one of the key parameters that determine the electrical efficiency of distribution networks. It is vital to execute power factor correction since lower values increase power losses and the need of compensation accordingly. Nature-inspired metaheuristics are the most commonly used optimization techniques to overcome power factor problem by reactive power and voltage control. Abdelhady et al. [33] estimate the optimum capacitor and the reactor values to control reactive power and power factor with Genetic Algorithm since the technique is compatible with real-time applications. Pires et al. [34] propose Particle Swarm Optimization for reactive power compensation and cost minimization of energy storage systems in distribution networks. The reason to select PSO in the study is the choice of wide set of possible solutions offered by multi-objective based optimization techniques. Li et al. [35] establish an adaptive discrete PSO algorithm for reactive power and voltage control of a wind farm by selecting the minimum reactive output as the control target and allowable voltage limits as constraints. Vlachogiannis et al. [36] present a general quantum genetic algorithm approach which estimates the control variables for reactive power compensation of IEEE $30-$ bus and 118- bus systems. The advantages of the proposed approach are listed as being effective with best solutions and suitable for use in both quantum and traditional computers.

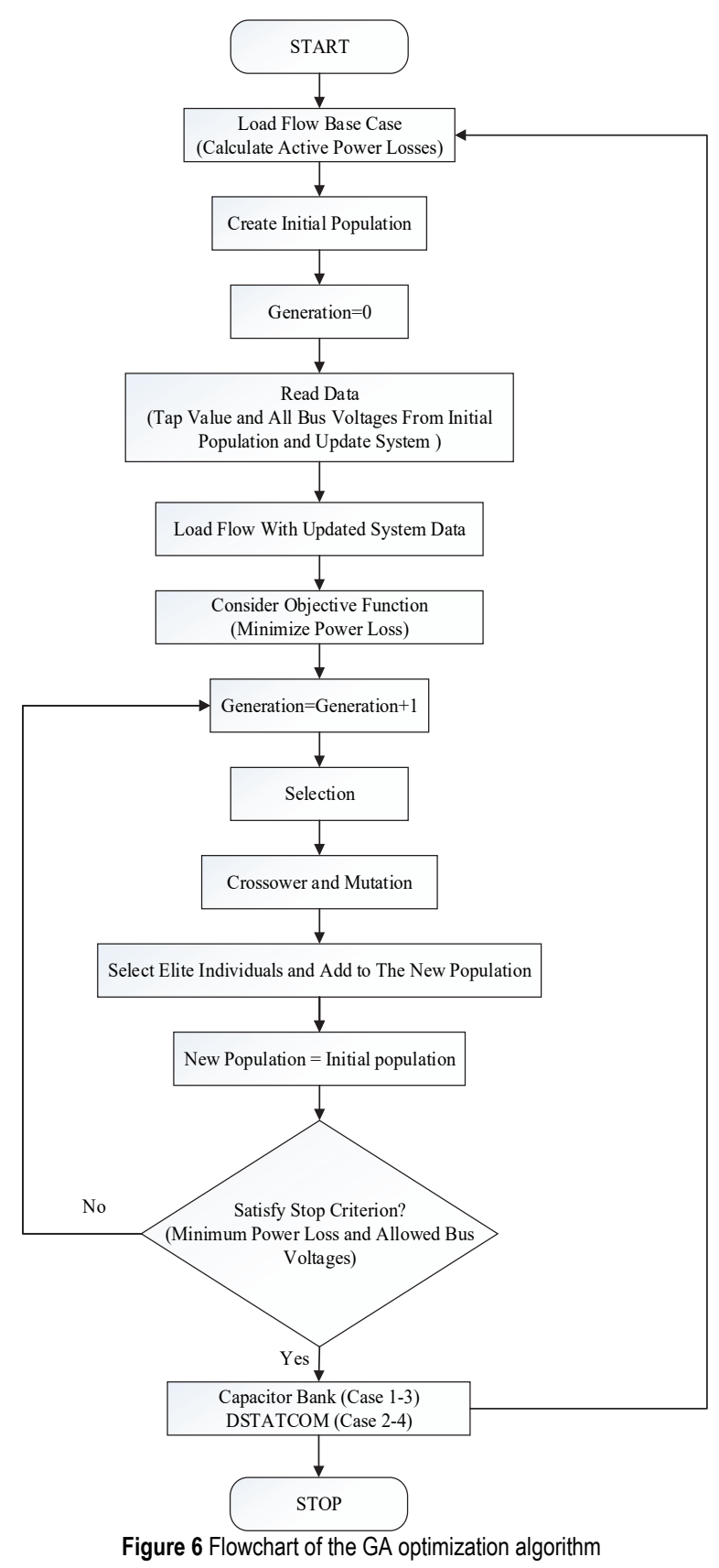

The literature supports the fact that evolutionary-based metaheuristics and swarm intelligence algorithms offer optimal solutions with a promising performance for reallife problems in electric power industry. In this paper, Genetic Algorithm, one of the most commonly used metaheuristic algorithms, is chosen to carry out power loss minimization in IEEE 34 bus test system by adjusting tap changer positions of the load tap changing transformer with tap value formulation in Section III.

GA is a random search algorithm which addresses natural selection and natural genetic mechanism to provide 
the global solution efficiently [37]. The advantages of GA algorithms in comparison with traditional optimization technics are as follows [38]:

- Optimization with both continuous parameters and discrete parameters,

- $\quad$ Searching the objective function in a wide solution area,

- Working without any additional differential information of the problem,

- Providing solutions to problems for more than one parameter and for each parameter at the same time.

Fig. 6 indicates the flowchart of GA optimization technique for determining tap value of load tap changing transformers within predetermined limits to minimize real power loss. In every cycle, real power losses are calculated with traditional power flow equations presented in Section III. Then the objective function is created by subtracting the generated power and the consumed value to determine the current real power losses in network. As explained in Section III, there are two constraints in this work:

- All bus voltages must be between 0.95 pu and 1.05 pu.

- Consumed power by load buses must be constant.

As the following step, these two constraints are added to the problem. Then, the steps of the algorithm given in the flowchart are repeated until the optimum tap values that satisfy both the objective function and constraints are obtained.

\section{FITNESS FUNCTIONS}

In this work, two fitness functions are used to evaluate the voltage profile and environmental profile of the system for each power loss minimization cases.

Bus Voltage Profile Index:

Bus voltage lower and upper limits are determined by distribution companies and these limits are $0.95 \mathrm{pu}$ and $1.05 \mathrm{pu}$ respectively in this work. Hence BVPI is formulated to

$$
\begin{aligned}
& B V P I_{\min }<B V P I=\frac{V_{\text {Bara }}}{V_{\text {min }}}<B V P I_{\max } \\
& \frac{0.95}{0.95}=1<B V P I=\frac{1.05}{0.95}=1.1
\end{aligned}
$$

Environmental Profile Indices:

Four environmental profile indices are formulated as $E P I, E P I_{2}$ and $E I_{3}$ in this work. EPI compares the $\mathrm{CO}_{2}$ savings between traditional optimization and $\mathrm{GA}$ optimization for all cases and $E P I_{2}$ compares the $\mathrm{CO}_{2}$ savings between Case 1 and Case 3 and $\mathrm{EPI}_{3}$ compares the $\mathrm{CO}_{2}$ savings between Case 2 and Case 4 .

$$
\begin{aligned}
& E P I=\left(1-\frac{C E_{G A}}{C E_{\text {traditional }}}\right) \cdot 100 \\
& E P I_{2}=\left(1-\frac{C E_{\text {case } 3}}{C E_{\text {case } 1}}\right) \cdot 100
\end{aligned}
$$

$$
E P I_{3}=\left(1-\frac{C E_{\text {case } 4}}{C E_{\text {case } 2}}\right) \cdot 100
$$

where $C E_{\text {traditional }}$ is the emission related to power losses with traditional optimization, $C E_{G A}$ is the emission related to power.

Photovoltaic and wind energy systems are the most preferred sustainable energy systems promising zero emission in the course of electrical energy generation. However, manufacturing, transportation and construction stages of these systems cause embodied emissions depending on their energy requirements. Thus, greenhouse payback times (GPBT) for Case 3 and Case 4 are calculated to determine the environmental profile more accurately. Current studies indicate that embodied energy factors of DGs are determined in terms of the energy used to produce the technology, the production year of the technology and the annual solar radiation received in the related location [39-42]. Considering all these parameters, emission factors for PV modules, BOS, inverters and wind energy system in this paper are selected to be $463 \mathrm{~kg} \mathrm{CO} 2 \mathrm{eq} / \mathrm{m}^{2}$ [39], $6.1 \mathrm{~kg}$ $\mathrm{CO}_{2} \mathrm{eq} / \mathrm{m}^{2}$ [40], $125 \mathrm{~kg} \mathrm{CO}{ }_{2} \mathrm{eq} / \mathrm{kWp}$ [41], $0.123 \mathrm{kgCO}_{2} / \mathrm{MJ}$ [42] respectively.

\section{RESULTS}

Tab. 1 indicates the 24 - hour real power losses of the test system with traditional optimization and GA optimization. According to the table, losses are minimized with GA optimization for all cases.

Table 124 - hour Real Power Losses of The Test System

\begin{tabular}{|c|c|c|c|}
\hline $\begin{array}{c}\text { Case } \\
\text { Number }\end{array}$ & $\begin{array}{c}\text { Losses with } \\
\text { traditional } \\
\text { optimization / } \\
\text { MW }\end{array}$ & $\begin{array}{c}\text { Losses with GA } \\
\text { optimization } \\
\text { / MW }\end{array}$ & $\begin{array}{c}\text { Loss minimization } \\
/ \%\end{array}$ \\
\hline Case 1 & 1068.028 & 1045.372 & 2.12 \\
\hline Case 2 & 1068.028 & 1006.938 & 5.72 \\
\hline Case 3 & 868.712 & 838.725 & 3.45 \\
\hline Case 4 & 868.712 & 810.391 & 6.71 \\
\hline
\end{tabular}

$B V P I$ of the system is investigated for all cases with both traditional optimization and GA optimization. The results indicate that 24 - hour bus voltage profile for all cases remains stable within allowed limits with each optimization algorithm. However, GA offers a more stable voltage profile with less fluctuations. Fig. 7 to Fig. 14 present 24 - hour BVPI for selected six buses in which voltage values change around the upper and lower limits.

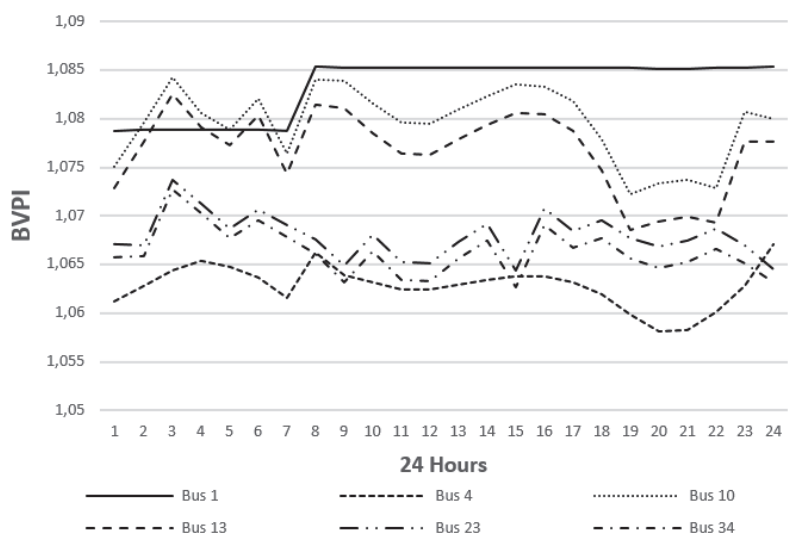

Figure 724 - hour BVPI for Case 1 with traditional optimization 


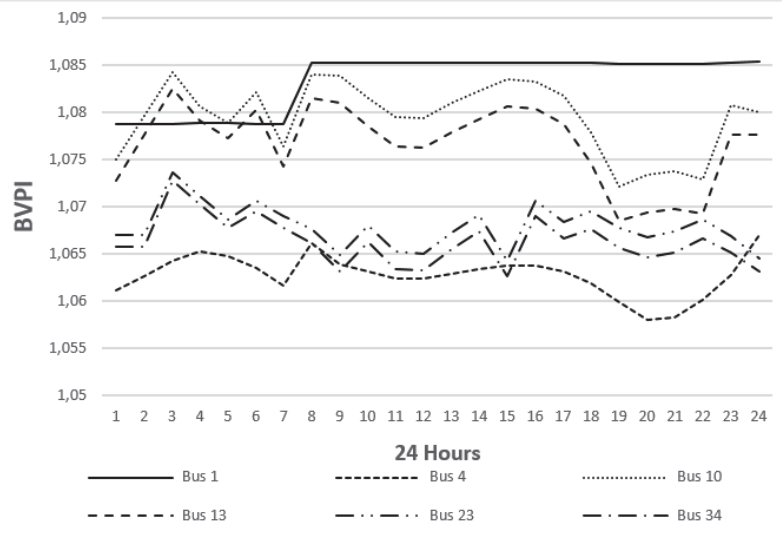

Figure 824 - hour BVPI for Case 1 with GA optimization

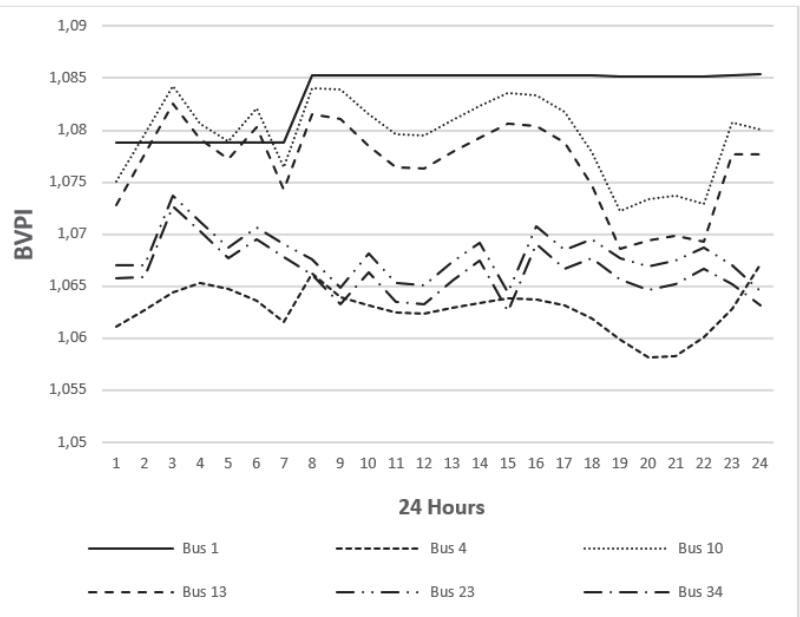

Figure 924 - hour BVPI for Case 2 with traditional optimization

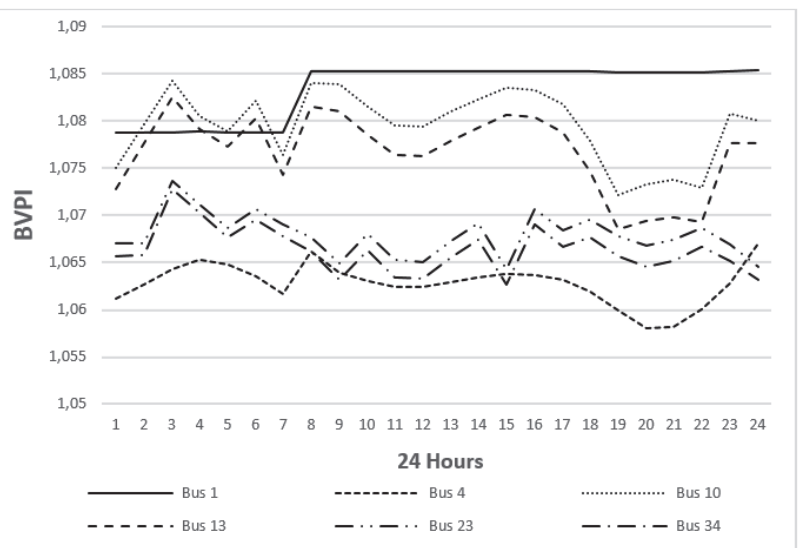

Figure 1024 - hour BVPI for Case 2 with GA optimization

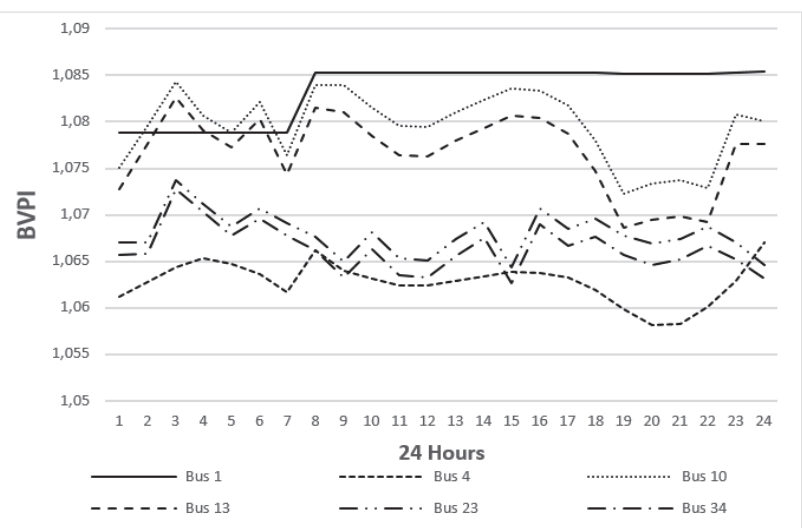

Figure 1124 - hour BVPI for Case 3 with traditional optimization

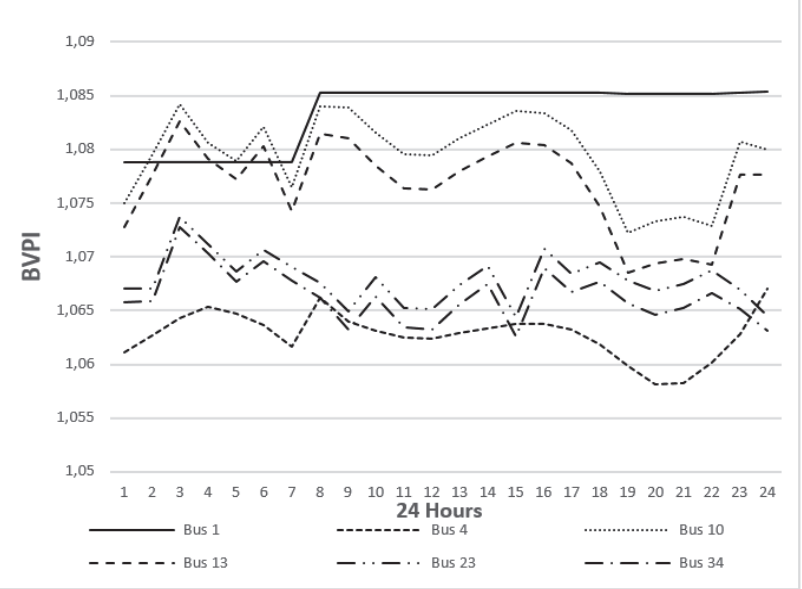

Figure 1224 - hour BVPI for Case 3 with GA optimization

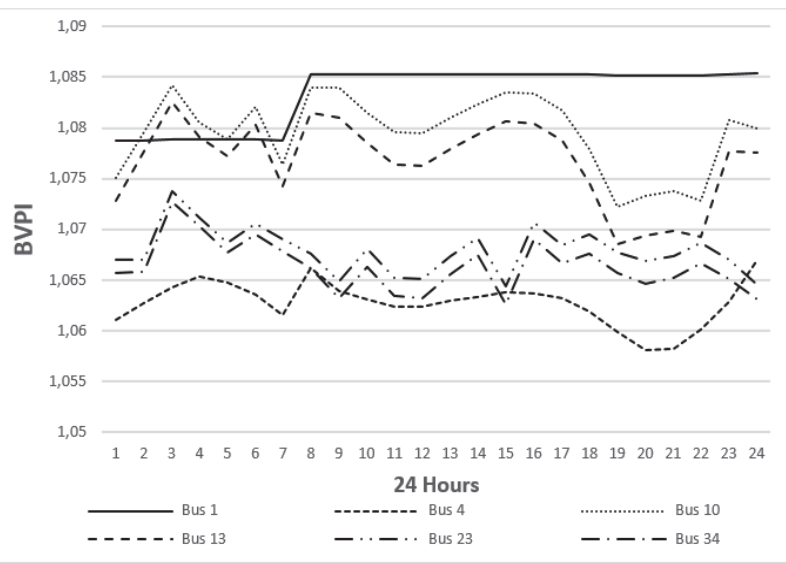

Figure 1324 - hour BVPI for Case 4 with traditional optimization

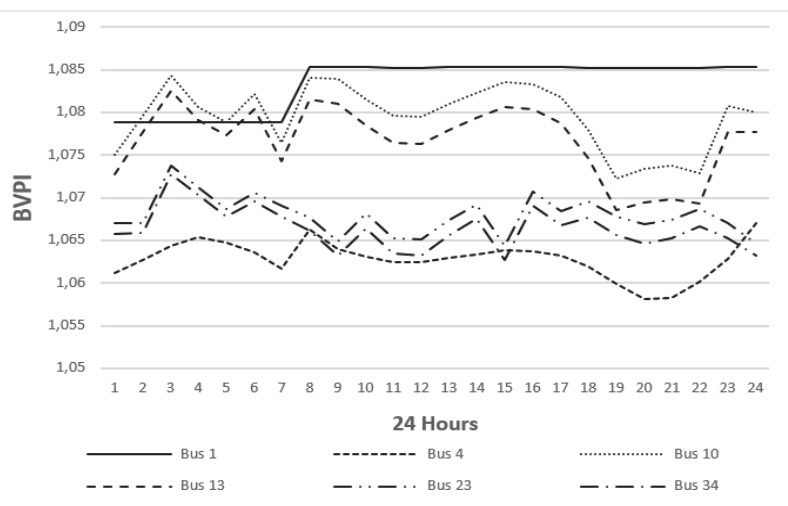

Figure 1424 - hour BVPI for Case 4 with GA optimization

Tab. 2 indicates EPI results for all cases. According to the table, optimization with GA offers a greener solution with less $\mathrm{CO} 2$ emissions.

\begin{tabular}{|l|l|}
\multicolumn{2}{c}{ Table 2 EPI RESULTS / \% } \\
\begin{tabular}{|l|l|}
\hline Case 1 & 2.2 \\
\hline Case 2 & 5.8 \\
\hline Case 3 & 3.5 \\
\hline Case 4 & 6.8 \\
\hline
\end{tabular}
\end{tabular}

$E P I_{2}$ and $E P I_{3}$ results in Tab. 3 indicate that DG makes a significant contribution to reduce $\mathrm{CO}_{2}$ emissions of the system.

Table $3 E P I_{2}$ AND EPI $I_{3}$ RESULTS / \%

\begin{tabular}{|l|l|}
\hline $\mathrm{EPI}_{2}$ & 19.8 \\
\hline $\mathrm{EPI}_{3}$ & 19.6 \\
\hline
\end{tabular}


Tab. 4 indicates daily $\mathrm{CO}_{2}$ savings by $\mathrm{DG}$ for Case 3 and Case 4 with GA optimization.

Table 4 DAILY $\mathrm{CO}_{2}$ SAVINGS BY DG OF CASE 3 AND CASE $4\left(\mathrm{TON} \mathrm{CO}_{2}\right)$

\begin{tabular}{|l|l|}
\hline Case 3 & 98.77 \\
\hline Case 4 & 93.949 \\
\hline
\end{tabular}

Embodied $\mathrm{CO}_{2}$ emissions of $50 \mathrm{~kW}$ wind system and $50 \mathrm{~kW}$ solar energy system are given in Tab. 5.

Table $5 \mathrm{CO}_{2}$ EMISSIONS OF DG IN THE TEST SYSTEM $\left(\mathrm{TON} \mathrm{CO}_{2}\right)$ Wind

133.743

According to Tab. 4 and Tab. 5, GPBT of DG in Case 3 and Case 4 with GA optimization is 0.435 years and 0.458 years respectively. This result shows that DG paybacks the embodied emissions in nearly 5.5 months, which is a very short period of time compared to its approximate lifetime, 20 years.

\section{CONCLUSION}

In this work, real power losses of IEEE 34 bus test system are minimized by adjusting tap changer positions of the load tap changing transformer with GA optimization for 4 different cases. $B V P I$ is formulated to check if all bus voltages are within allowed limits after minimization with GA optimization. Besides environmental profiles of all cases are compared by three different indices to determine the optimal case with minimum $\mathrm{CO}_{2}$ emissions and maximum power savings.

The 24 - hour real power losses of the test system are investigated for all cases with tap values obtained by both traditional optimization and GA optimization. The results indicate that GA optimization minimizes losses better than traditional optimization by $2.121 \%, 5.179 \%, 3.451 \%$ and $6.713 \%$ for Case 1, Case 2, Case 3 and Case 4 respectively. Besides, the improved performances of Case 2 and Case 4 indicate that the integration of DSTATCOM and/or DG units provides a significant real power saving in distribution networks. However, 24 - hour voltage behaviour of the system after minimization for all cases must be monitored to determine the best case.

$B V P I$ results indicate that all bus voltages are within allowed limits, between $0.95 \mathrm{pu}$ and $1.05 \mathrm{pu}$, with each optimization algorithm for every single case researched. However, it is observed that GA, an evolutionary-based algorithm, fits the non-linear power loss minimization problem better than traditional technique.

EPI compares the $\mathrm{CO}_{2}$ savings obtained with the two optimization algorithms for all cases. According to Table II, GA improves environmental profile of the test system in direct proportion to power minimization success in all cases with $2.2 \%$ more $\mathrm{CO}_{2}$ savings in the worst case. $E P I_{2}$ and $\mathrm{EPI}_{3}$ evaluate the environmental effect of DG integration to the system considering the embodied greenhouse gas emissions. The results show that DG allocation contributes almost $20 \% \mathrm{CO}_{2}$ savings with $G P B T$ of 0.435 years and 0.458 years for Case 3 and Case 4 with GA optimization respectively. Considering that the lifetimes of solar and wind energy systems are approximately 20 years, 0.458 years is a reasonable margin to payback for the embodied emissions. In this manner,
Case 4, test system with DG and DSTATCOM, is established as the best case for real power loss minimization with proper $B V P I$ and $E P I$.

In conclusion, it is supported that power loss minimization is a non-linear problem which must be optimized with evolutionary-based metaheuristics or swarm intelligence algorithms instead of traditional methods. Besides, it is indicated that the integration of FACTs devices in place of traditional power conditioning devices is efficient option in terms of power loss minimization, voltage profile and environmental profile. In this work, DG unit allocation is also investigated and found out that load tap changing with evolutionary-based metaheuristics or swarm intelligence algorithms provides significant minimization in power losses and greenhouse gas emissions without any changes in the present conditions of power systems. Since DGs are the most promising solutions for distribution networks in near future under rapidly increasing climate change concerns, it is likely to see evolutionary-based metaheuristics or swarm intelligence algorithms in real time applications more commonly to utilize DGs efficiently without additional costs.

In future work, it is aimed to investigate optimal allocation of DG units and FACTs devices with an advanced version of evolutionary-based metaheuristics to maximize benefits in voltage profile, environmental profile and economic profile.

\section{REFERENCES}

[1] Mahdad, B., Bouktir, T., Srairi, K., \& Benbouzid, M. E. (2010). Dynamic strategy based fast decomposed GA coordinated with FACTS devices to enhance the optimal power flow. Energy Convers Manage, 51(7), 1370-1380. https://doi.org/10.1016/j.enconman.2009.12.018

[2] Sayah, S. \& Zehar, K. (2008). Modified differential evolution algorithm for optimal power flow with non-smooth cost functions.Energy Convers Manage, 49(11), 3036-3042. https://doi.org/10.1016/j.enconman.2008.06.014

[3] Chen, G., Liu, L., Song, P. \& Du, Y. (2014). Chaotic improved PSO-based multi-objective optimization for minimization of power losses and $\mathrm{L}$ index in power systems.Energy Conversion and Management, 86, 548-560. https://doi.org/10.1016/j.enconman.2014.06.003

[4] Leisse, I., Samuelsson, O., \& Svensson, J. (2010). Electricity meters for coordinated voltage control in medium voltage networks with wind power. IEEE PES Innovative Smart Grid Technologies Conference Europe, ISGT Europe. https://doi.org/10.1109/ISGTEUROPE.2010.5638977

[5] Szuvovivski, I., Fernandes, T. S. P., \& Aoki, A. R. (2012). Simultaneous allocation of capacitors and voltage regulators at distribution networks using Genetic Algorithms and Optimal Power Flow. International Journal of Electrical Power \& Energy Systems, 40(1), 62-69. https://doi.org/10.1016/j.jijepes.2012.02.006

[6] Bravo, R. J., Robles, S. A., \& Bialek, T. (2014). VAr support from solar PV inverters. 2014 IEEE 40th Photovoltaic Specialist Conference, PVSC 2014, 2672-2676. https://doi.org/10.1109/PVSC.2014.6925479

[7] Jie, B., Tsuji, T., \& Uchida, K. (2018). Coordinated voltage control by inverters and FACTS devices in distribution system. China International Conference on Electricity Distribution, CICED, 201805280000368, 1872-1875. https://doi.org/10.1109/CICED.2018.8592414 
[8] Yu, S., Chau, T. K., Fernando, T., Savkin, A. V., \& Iu, H. H. (2017). Novel Quasi-Decentralized SMC-BasedFrequency and Voltage Stability Enhancement Strategies Using Valve Position Control and FACTS Device. IEEE Access, 5, 946955. https://doi.org/10.1109/ACCESS.2016.2622709

[9] Shaik, M. R. \& Reddy, A. S. (2017). Optimal placement and sizing of FACTS device to overcome contingencies in power systems. International Conference on Signal Processing, Communication, Power and Embedded System, SCOPES 2016 - Proceedings, 838-842. https://doi.org/10.1109/SCOPES.2016.7955559

[10] Abdelhady, S., Osama, A., Shaban, A., \& Elbayoumi, M. A. (2020). Real-Time Optimization of Reactive Power for An Intelligent System Using Genetic Algorithm. IEEE Access, 8, 11991-11999. https://doi.org/10.1109/ACCESS.2020.2965321

[11] Devi, S. \& Geethanjali, M. (2014). Optimal location and sizing determination of Distributed Generation and DSTATCOM using Particle Swarm Optimization algorithm. International Journal of Electrical Power \& Energy Systems, 62, 562-570. https://doi.org/10.1016/j.ijepes.2014.05.015

[12] Ahmadi, H., Martí, J.R., \& Dommel, H. W. (2015). A Framework for Volt-VAR Optimization in Distribution Systems. IEEE Trans. Smart Grid, 6(3), 1473-1483. https://doi.org/10.1109/TSG.2014.2374613

[13] Distribution System Analysis Subcommittee. (2010). IEEE 34NodeTestFeeder. http://ewh.ieee.org/soc/pes/dsacom/testfeeders/index.html

[14] Das, J. C. (2011). Power System Analysis Short-Circuit Load Flow and Harmonics, Second Edition, ISBN-13: 9781138075047

[15] Laksmi, S. \& Ganguly, S. (2019). An On-Line Operational Optimization Approach for Open Unified Power Quality Conditioner for Energy Loss Minimization of Distribution Networks.IEEE Transactions on Power Systems, 34(6), 4784-4795. https://doi.org/10.1109/TPWRS.2019.2919786

[16] Singh, J. \& Tiwari, R. (2019). Real power loss minimisation of smart grid with electric vehicles using distribution feeder reconfiguration. IET Generation, Transmission \& Distribution, 13, 4249-4261. https://doi.org/10.1049/iet-gtd.2018.6330

[17] Cabezas, S. F. R. \& Alfredo, C. H. F. (2019). Minimization of Losses in Power Systems by Reactive Power Dispatch using Particle Swarm Optimization. 2019 54th International Universities Power Engineering Conference, UPEC 2019 Proceedings. https://doi.org/10.1109/UPEC.2019.8893527

[18] Qiao, F. \& Ma, J. (2020). Voltage/Var Control for Hybrid Distribution Networks Using Decomposition-Based Multiobjective Evolutionary Algorithm. IEEE Access, 8, 12015-12024. https://doi.org/10.1109/ACCESS.2020.2965965

[19] Emiroglu, S., Uyaroglu, Y., \& Ozdemir, G. (2017). Distributed Reactive Power Control based Conservation Voltage Reduction in Active Distribution Systems. Advances in Electrical and Computer Engineering, 17(4), 99-106. https://doi.org/10.4316/AECE.2017.04012

[20] Tosun, S. (2012). Elektrik enerji dağıtım sisteminde ekonomik aktifgüç dağıtımının genetik algoritma ile belirlenmesi. PhD thesis, Sakarya University.

[21] Slowik, A. \& Kwasnicka, H. (2018). Nature inspired methods and their industry applications Swarm intelligence algorithms. IEEE Transactions on Industrial Informatics, 14(3), 1004-1015. https://doi.org/10.1109/TII.2017.2786782

[22] Govindan, K., Jafarian, A., \& Nourbakhsh, V. (2019) Designing a sustainable supply chain network integrated with vehicle routing: A comparison of hybrid swarm intelligence metaheuristics. Computers \& Operations Research, 110, 220-235. https://doi.org/10.1016/j.cor.2018.11.013

[23] Dulebenets, M. A. (2018). A Comprehensive Evaluation of Weak and Strong Mutation Mechanisms in Evolutionary
Algorithms for Truck Scheduling at Cross-Docking Terminals. IEEE Access, 6, 65635-65650. https://doi.org/10.1109/ACCESS.2018.2874439

[24] Zhao, X., Wang, C., Su, J., \& Wang, J. (2019). Research and application based on the swarm intelligence algorithm and artificial intelligence for wind farm decision system. Renewable Energy, 134, 681-697. https://doi.org/10.1016/j.renene.2018.11.061

[25] Brezočnik, L., Fister, I., \& Podgorelec, V. (2018). Swarm intelligence algorithms for feature selection: a review. Applied Sciences, 8(9), 1521. https://doi.org/10.3390/app8091521

[26] Dulebenets, M. A. (2019). A Delayed Start Parallel Evolutionary Algorithm for just-in-time truck scheduling at a cross-docking facility. International Journal of Production Economics, 212, 236-258. https://doi.org/10.1016/j.ijpe.2019.02.017

[27] Vahdani, B. \& Shahramfard, S. (2019). A truck scheduling problem at a cross-docking facility with mixed service mode dock doors.Engineering Computations, 36(1), 1977-2009. https://doi.org/10.1108/EC-08-2018-0355

[28] Anandakumar, H. \& Umamaheswari, K. (2018).A bioinspired swarm intelligence technique for social aware cognitive radio handovers. Computers \& Electrical Engineering, 71, 925-937. https://doi.org/10.1016/j.compeleceng.2017.09.016

[29] Alaee, S., Hooshmand, R., \& Hemmati, R. (2016).Stochastic transmission expansion planning incorporating reliability solved using SFLA meta-heuristic optimization technique.in CSEE Journal of Power and Energy Systems, 2(2), 79-86. https://doi.org/10.17775/CSEEJPES.2016.00025

[30] Wang, L. \& Singh, C. (2007). Compromise between cost and reliability in optimum design of an autonomous hybrid power system using mixed-integer PSO algorithm. 2007 International Conference on Clean Electrical Power, ICCEP '07, 682-689. https://doi.org/10.1109//CCEP.2007.384284

[31] Zhang, B., Yang, Y., \& Lu, G. (2008). Dynamic control of wind/photovoltaic hybrid power systems based on an advanced particle swarm optimization. Proceedings of the IEEE International Conference on Industrial Technology. https://doi.org/10.1109/ICIT.2008.4608443

[32] Abdelkader, A., Rabeh, A., Ali, D. M., \& Mohamed, J. (2018). Multi-objective genetic algorithmbased sizing optimization of a stand-alone wind/PV power supply system with enhanced battery/supercapacitor hybrid energy storage. Energy, 163, 351-363. https://doi.org/10.1016/j.energy.2018.08.135

[33] Abdelhady, S., Osama, A., Shaban, A., \& Elbayoumi, M. (2020). A Real-Time Optimization of Reactive Power for An Intelligent System Using Genetic Algorithm. IEEE Access, 8, 11991-12000. https://doi.org/10.1109/ACCESS.2020.2965321

[34] Pires, V. F., Pombo, A. V., \& Lourenco, J. M. (2019). Multiobjective optimization with post-pareto optimality analysis for the integration of storage systems with reactive-power compensation in distribution networks. Journal of Energy Storage, 24, 100769. https://doi.org/10.1016/j.est.2019.100769

[35] Li, J., Huang, H., Lou, B., Peng, Y., Huang, Q., \& Xia, K. (2019). Wind Farm Reactive Power and Voltage Control Strategy Based on Adaptive Discrete Binary Particle Swarm Optimization Algorithm. 2019 Asia Power and Energy Engineering Conference, APEEC 2019, 1, 99-102. https://doi.org/10.1109/APEEC.2019.8720712

[36] Vlachogiannis, J. G. \& Ostergaard, J. (2009). Reactive power and voltage control based on general quantum genetic algorithms. Expert Systems with Applications, 36(3), 61186126. https://doi.org/10.1016/j.eswa.2008.07.070

[37] Mitchell, M. (1996). An Introduction to Genetic Algorithms, Cambridge, MA: MIT Press.

[38] Guo, P., Wang, X., \& Han, Y. (2010). The enhanced genetic algorithms for the optimization design. Proceedings - 2010 
3rd International Conference on Biomedical Engineering and Informatics, BMEI 2010, 7(Bmei), 2990-2994. https://doi.org/10.1109/BMEl.2010.5639829

[39] Battisti, R. \& Corrado, A. (2005). Evaluation of technical improvements of photovoltaic systems through life cycle assessment methodology. Energy, 30(7), 952-67. https://doi.org/10.1016/j.energy.2004.07.011

[40] Alsema, E. A. \& de Wild-Scholten, M. J. (2006). Environmental impacts of crystalline silicon photovoltaic module production. Proceedings of the 13th CIRP International Conference on Life Cycle Engineering, LCE 2006, January, 103-108. https://doi.org/10.1557/proc-0895-g03-05

[41] Bizzarri, G. \& Morini G. L. (2007). A Life Cycle Analysis of roof integrated photovoltaic systems. International Journal of Environmental Technology and Management, 7(1/2), 134-146. https://doi.org/10.1504/IJETM.2007.013241

[42] Chen, G. Q., Yang, Q., \& Zhao, Y. H. (2011). Renewability of wind power in China: A case study of nonrenewable energy cost and greenhouse gas emission by a plant in Guangxi. Renewable and Sustainable Energy Reviews, 15(5), 2322-2329. https://doi.org/10.1016/j.rser.2011.02.007

\section{Contact information:}

Talha Enes GÜMÜŞ, Res. Asst., MSc.

(Corresponding author)

Institution Electrical and Electronics Eng. Department, Eng. Faculty, Sakarya

University, Turkey

E-mail: tgumus@sakarya.edu.tr

\section{Ceyda Aksoy TIRMIKÇI, PhD}

Institution Electrical and Electronics Eng. Department, Eng. Faculty, Sakarya

University, Turkey

E-mail: caksoy@sakarya.edu.tr

Cenk YAVUZ, Assoc. Prof. Dr.

Institution Electrical and Electronics Eng. Department, Eng. Faculty, Sakarya

University, Turkey

E-mail: cyavuz@sakarya.edu.tr

Mehmet Ali YALÇIN, Prof. Dr.

Institution Electrical and Electronics Eng. Department, Eng. Faculty, Sakarya

University, Turkey

E-mail: yalcin@sakarya.edu.tr

Mustafa TURAN, Asst. Prof. Dr.

Institution Electrical and Electronics Eng. Department, Eng. Faculty, Sakarya

University, Turkey

E-mail: turan@sakarya.edu.tr 